\title{
UTILIZAÇÃO DE DUAS DIFERENTES MEGADOSES DE VITAMINA C NA RAÇÃO DE ALEVINOS DE TILÁPIA DO NILO (OREOCHROMIS NILOTICUS) SUBMETIDOS À INFECÇÃO EXPERIMENTAL POR EDWARDSIELLA TARDA
}

\author{
L.C.R.I. Baraúna ${ }^{1}$, D.S.P. Costa ${ }^{1}$, J.V. Carvalho ${ }^{1}$, A.D. Lira ${ }^{2}$, T.R. Almeida ${ }^{2}$, \\ A.F. Garcez Neto ${ }^{2}$, S.S. Laborda1 ${ }^{1}$, R.C.B. Albinati ${ }^{2}$, E.M.D. Oliveira ${ }^{1}$, M.C.A. Silva ${ }^{1}$
}

${ }^{1}$ Universidade Federal da Bahia, Escola de Medicina Veterinária, Departamento de Medicina Veterinária Preventiva, Av. Adhemar de Barros, 500, CEP 40170-110, Salvador, BA, Brasil. E-mail: lilacrib@hotmail.com

\section{RESUMO}

\begin{abstract}
Objetivando avaliar o efeito da suplementação com megadoses de vitamina C na dieta de alevinos de Tilápia do Nilo (Oreochromis niloticus), frente à infecção experimental por Edwardsiella tarda, foram realizados dois experimentos. Cada experimento foi composto por quatro grupos distintos: aqueles pertencentes aos grupos 1 e 4 receberam apenas ração comercial apresentando cerca de $300 \mathrm{mg}$ de vitamina C por quilo de ração, enquanto os animais pertencentes aos grupos 2 e 3 receberam a mesma ração suplementada com $1.500 \mathrm{mg}$ e $3.000 \mathrm{mg}$, respectivamente, de vitamina C (Lutavit@ C Monophosphate - BASF) por quilo de ração. No primeiro experimento os animais receberam a dieta durante 14 dias consecutivos, sendo desafiados no $15^{\circ}$ dia, enquanto no segundo experimento os animais só foram desafiados pela suspensão bacteriana após um intervalo de mais 14 dias findo o mesmo período de suplementação com vitamina C. Os resultados mostraram que, embora não haja diferença significativa $(p>0,05)$ com relação às concentrações de vitamina $C$, o intervalo entre o final do período de suplementação com megadoses de vitamina C na ração (Nutripeixe AL55 - PURINA) e a exposição à suspensão bacteriana apresentou diferença significativa $(\mathrm{p}<0,05)$ sobre a infecção experimental $\operatorname{com} E$. tarda em alevinos de Tilápia do Nilo (O. niloticus).
\end{abstract}

PALAVRAS-CHAVE: Tilápias do Nilo (Oreochromis niloticus), Edwardsiella tarda, vitamina C.

\section{ABSTRACT}

USE OF TWO DIFFERENT MEGADOSES OF VITAMIN C IN THE FEED FOR FINGERLINGS NILE TILAPIA (OREOCHROMIS NILOTICUS) SUBMITTED TO EXPERIMENTAL INFECTION BY EDWARDSIELLA TARDA. Aiming to evaluate the effect of supplementation with megadoses of vitamin C on the diet of fingerlings from Nile Tilapia (Oreochromis niloticus), at the experimental infection by Edwardsiella tarda, two experiments were performed. Each experiment was composed by four distinct groups: those belonging to groups 1 and 4 received only commercial diet featuring about $300 \mathrm{mg}$ of vitamin C per kilogram of feed, while the animals belonging to groups 2 and 3 received the same diet supplemented with $1,500 \mathrm{mg}$ and $3,000 \mathrm{mg}$, respectively, of vitamin $\mathrm{C}$ (Lutavit ${ }^{\circ}$ C Monophosphate - BASF) per kilogram of feed. In the first experiment the animals received the diet for 14 consecutive days, being infected on the 15th day, while in the second experiment the animals were infected by the bacterial suspension after an interval of more 14 days after the same period of supplementation with vitamin $C$. The results showed that although there isn't a significant difference $(p>0,05)$ with respect to the concentrations of vitamin $C$, however the interval between the end of supplementation with megadoses of vitamin $C$ in the diet (Nutripeixe AL55 - PURINA) and bacterial exposure showed significant difference $(p<0,05)$ on the experimental infection with E. tarda in fingerlings of Nile Tilapia (O. niloticus).

KEY WORDS: Nile Tilapia (Oreochromis niloticus), Edwardsiella tarda, vitamin C.

\footnotetext{
${ }^{2}$ Universidade Federal da Bahia, Escola de Medicina Veterinária, Departamento de Produção Animal, Salvador, BA,
} Brasil. 


\section{INTRODUÇÃO}

Além de ser um importante fator de desenvolvimento sócio-econômico para o país, a aquicultura é uma alternativa para incrementar os índices de consumo de proteínas de origem animal. Apesar das crises econômicas e do surgimento de novas enfermidades, a atividadeé considerada um dos sistemas de produção de alimentos que mais cresce no mundo, e que poderá contribuir muito com a crescente demanda mundial de pescado neste milênio (SouzA, 2002).

Um dos problemas mais sérios que se manifesta quando se pretende intensificarqualquer processo de confinamento de peixes é o aparecimento de doenças no plantel. Isso ocorre devido ao fato dos peixes serem cultivados geralmente em regime de confinamento intensivo, ficando submetidos a um estresse crônico, com reflexos em sua homeostasia, ocasionando uma maior sensibilidade e, por consequência, uma menor resistência às enfermidades em geral. Tais enfermidades, dependendo da etiologia, podem se constituir em uma grave ameaça ao sucesso das explorações aquícolas (PAVANELliet al., 2000).

As enfermidades bacterianas são responsáveis por graves mortalidades, tanto em peixes de vida livre como nos de criação. Aágua, principalmente quando contém excesso de matéria orgânica, é um meio ideal para o crescimento de muitos gêneros de bactérias (RoBerTs, 1981). Além da água, o muco da superfície corporal e o trato digestivo dos peixes albergam uma ampla microbiota bacteriana. As bactérias saprófitas são responsáveis por infecções secundárias ou oportunistas, sobretudo quando os peixes estão debilitados pelo estresse ou por alguma enfermidade prévia, especialmente quando há solução de continuidade (Moraes; Martins, 2004).

Edwardsielose é o nome dado às infecções causadas por bactérias do gênero Edwardsiella. Estas bactérias são bacilos móveis, Gram-negativas e que pertencem ao grupo das enterobactérias. Ocorrem na água, nos sedimentos dos tanques, no intestino e fezes dos peixes e parecem ser um componente normal da microbiota existente à superfície destes. Também habitam ointestino de invertebrados, répteis, anfíbios e aves (Roberts, 1981; PAVANelli et al., 1998; Kubitza, 2000). Esta bactéria provoca a chamada septicemia dos peixes de água quente, que se manifesta tipicamente em temperaturas entre $23 \mathrm{a} 30^{\circ} \mathrm{C}$, especialmente quando há grande quantidade de matéria orgânica naágua e os hospedeiros estãoem situação de estresse. Considera-se que pode atingir todos os peixes de águas quentes, especialmente o bagre do canal, a carpa, a tilápia, e outros peixes de criação. Pode também provocar doenças em outros hospedeiros como jacarés, serpentes, bois, aves e no homem, cau- sando gastrenterite e meningite (PAVAnElliet al.,1998; KubiTZA, 2000).

Um novo conceito de balanceamento de rações vem se estabelecendo, com princípios pautados em nutrição, saúde e responsabilidade ambiental. Para tanto, as pesquisas científicas vêm agregando diferentes áreas como a hematologia e a imunologia com o intuito de auxiliar o entendimento sobre a nutrição e o desenvolvimento de estratégias para mitigar os efeitosdoestresseeaumentararesistênciaimunológica dos peixes (FALCON, 2007). Ousodeimunoestimulantes na piscicultura é um meio efetivo para aumentar a imunocompetência e a resistência às doenças nos peixes. Porém, pouco se sabe quanto a sua eficácia, limitações de uso e as respostas em longo prazo. Estudos mais detalhados são necessários para verificar quanto, como, para quê e qual imunoestimulante deve ser utilizado (ReQue, 2005).

Oácido ascórbico (vitamina C) é conhecido como promotor de numerosos processos bioquímicos e fisiológicos, tanto em animais como em plantas. A maioria dos animais pode sintetizar essa vitamina em quantidades suficientes para prevenir os sinais clínicos de deficiência, conhecida como escorbuto. Entretanto, primatas, porcos da índia, peixes, camarões, morcegos, aves e alguns insetos necessitam de uma fonte dietética de vitamina $\mathrm{C}\left(\mathrm{O}^{\prime} \mathrm{KEEFE}\right.$, 2001).

A vitamina $C$ assume importância considerável em razão da ação que exerce em vários processos metabólicos. Esta vitamina é considerada um nutriente indispensável e essencial para a maioria das espécies de peixes, uma vez que estes não a sintetizam devido à ausência da enzima L-gulonolactona oxidase, a qual atua em sua formação a partir da glicose (Lovell, 1973; Pezzato et al., 2004; Shiau; Lin, 2006).

Oobjetivo deste experimento foi verificar a eficácia da utilização de doses elevadas de vitamina C (1.500 $\mathrm{mg} / \mathrm{kg}$ e $3.000 \mathrm{mg} / \mathrm{kg}$ ) na ração dealevinos de Tilápia do Nilo (O. niloticus) submetidos à inoculação experimental com cultura de Edwardsiella tarda, além de verificar a possibilidade de transmissão horizontal no meio aquático da infecção em peixes não inoculados quando em convívio com peixes inoculados com a bactéria.

\section{MATERIAL E MÉTODOS}

Os dois experimentos foram conduzidos de setembro a outubro de 2007 no Laboratório de Sanidade de Organismos Aquáticos - LASOA, juntamente com o Laboratório de Bacterioses - LABAC, ambos da Escola de Medicina Veterinária da Universidade Federal da Bahia (UFBA). 
Para a instalação dos experimentos, algumas atividades como limpeza e desinfecção dos tanques, manutenção do filtro biológico e dos aeradores, além do enchimento dos tanques para a aclimatação dos peixes, foram anteriormente realizadas.

No primeiro experimento os animais receberam a suplementação de vitamina C (Lutavit C Monophosphate - BASF) durante 14 dias consecutivos e em seguida foram desafiados, enquanto que o segundo difere do primeiro apenas no tempo do desafio que foi realizado 14 dias após o término da suplementação, sendo que ambos tiveram início no mesmo dia.

Foram utilizados no total 144 alevinos de Tilápias do Nilo (O. niloticus), 72 para cada experimento, com peso médio inicial de $17,64( \pm 4,67 \mathrm{~g})$ e tamanho inicial de 10,11 $( \pm 0,99 \mathrm{~cm})$, distribuídos aleatoriamente em 8 tanques de 200 L de capacidade, abastecidos com água do reservatório do laboratório. Durante os experimentos foram avaliados diariamente os seguintes parâmetros aquáticos, com suas respectivas variações: oxigênio dissolvido 5,49 ( $\pm 0,46 \mathrm{mg} / \mathrm{L}), \mathrm{pH} 7,19$ $( \pm 0,08)$ e temperatura $24,72\left( \pm 0,18^{\circ} \mathrm{C}\right)$, sendo estes parâmetros mantidos dentro da faixa de conforto para a espécie. Alevinos foram alimentados diariamente, com ração comercial (Nutripeixe AL55-Purina) na concentração de $2 \%$ da biomassa, e as quantidades foram reformuladas após biometrias quinzenais. Os alevinos foram identificados individualmente por meio de técnica de marcação externa com 2 miçangas coloridas, transfixadas com nylon cirúrgico 2.0 à musculatura dos peixes na inserção da nadadeira caudal na posição dorsal segundo FARIA et al. (2003).

Foi utilizada como agente infectante a bactéria $E$. tarda, isolada e identificada a partir de amostra de rim de tilápia (Albinati et al., 2006). As suspensões bacterianas foram preparadas em solução salina a 0,85\% estéril e os inóculos empregados no primeiro e no segundo experimento foram de 2,0 x $10^{7} \mathrm{UFC} / \mathrm{mL}$ e $1,3 \times 10^{8} \mathrm{UFC} / \mathrm{mL}$, respectivamente.

Para cada experimento foram formados os grupos 1, 2, 3 e 4 (grupo controle), cada um contendo 18 alevinos. Inicialmente os alevinos foram mantidos durante 7 dias em período de adaptação, recebendo ração comercial $(300 \mathrm{mg} / \mathrm{kg}$ de vitamina C). Após esse período, todos os alevinos dos grupos 2 e 3 receberam a ração comercial suplementada com 1.500 e 3.000 $\mathrm{mg} / \mathrm{kg}$ de vitamina $\mathrm{C}$, respectivamente, por 14 dias consecutivos, enquanto que os animais dos grupos 1 e 4 continuaram a receber a ração comercial. No dia 21, os animais dos grupos 1, 2 e 3 do experimento 1 foram inoculados, por via intraperitoneal, com $1 \mathrm{~mL}$ da suspensão bacteriana na concentração de 2,0 x 10 UFC/mL, enquanto que os alevinos do grupo controle foram inoculados com $1 \mathrm{~mL}$ de solução salina $0,85 \%$ estéril, criando-se a mesma situação de estresse dos outros grupos. Nesse mesmo dia, foi interrompida a suplementação de vitamina $C$ aos animais do experimento 2. A partir do momento da inoculação, os peixes foram observados diariamente para verificação de eventuais manifestações clínicas, assim como alterações comportamentais, morbidade e mortalidade, ocasionadas pela bactéria.

O desafio do experimento 2 foi realizado 14 dias após o término da suplementação com a vitamina $C$, ou seja no dia 36 . Os animais dos grupos 1, 2 e 3 também foram inoculados, por via intraperitoneal, com $1 \mathrm{~mL}$ da suspensão bacteriana na concentração de $1,3 \times 10^{8} \mathrm{UFC} / \mathrm{mL}$, enquanto que para os alevinos do grupo controle foram adotados os mesmos critérios descritos no experimento 1.

Em cada experimento, vinte e um dias após a inoculação, os alevinos de todos os grupos, inclusive os controles, foram sacrificados individualmente, através da indução anestésica com Eugenol ${ }^{\circledR}$ (Biodinâmica), até atingirem o estágio de anestesia profunda (VIDAL et al., 2007). Após o sacrifício foram feitas colheitas estéreis de fígado com alça de platina calibrada $(100 \mu \mathrm{L})$ e transferidas para tubos contendo $0,9 \mathrm{~mL}$ de solução salina a $0,85 \%$ estéril. Após a homogeneização do material, foram realizadas sucessivas diluições decimais até $10^{-4}$. De cada diluição foi retirado $0,1 \mathrm{~mL}$, sendo em seguida semeado pela técnica de espalhamento com alça de Drigalsky em duas placas com meio ÁgarSS (Salmonela-Shigella), as quais foram incubadas a temperatura ambiente, por 48 horas, e realizada, posteriormente, a contagem das UFC. Para identificação, amostras de colônias individuais, com características morfológicas e tintoriais típicas, foram submetidas posteriormente ao teste de oxidase e às provas bioquímicas para confirmação da espécie bacteriana (CARTER, 1969).

\section{RESULTADOS}

Os alevinos de Tilápias do Nilo (O. niloticus) dos experimentos 1 e 2, inoculados com as concentrações bacterianas, não apresentaram alterações comportamentais ou morfológicas durante todo o experimento, assim como os alevinos dos respectivos grupos controles.

Os resultados das contagens de UFC em tecido hepático de Tilápias do Nilo encontrados nos dois experimentos estão organizados nas Tabelas 1 e 2 .

A comparação dos log10 das UFC entreas diferentes doses de vitamina C (exceto controle) empregadas nos três diferentes grupos do experimento 1 (Teste de Kruskal-Wallis) não apresentou diferença significativa ( $p=0,1718)$, assim como também não mostrou diferença significativa para o experimento 2 ( $\mathrm{p}=$ 0,1411). 
Tabela 1 - Número de unidades formadoras de colônias (U.F.C.) de Edwardsiella tarda isoladas de tecido hepático de alevinos de Tilápia do Nilo (Oreochromis niloticus) alimentados com doses normais de manutenção (300 mg/ kg) e megadoses de vitamina $\mathrm{C}(1.500 \mathrm{mg} / \mathrm{kg}$ e $3.000 \mathrm{mg} / \mathrm{kg})$ durante 14 dias, experimentalmente infectados no $22^{\circ}$ dia do estudo (Experimento 1).

\begin{tabular}{ccccc}
\hline Peixes & $\begin{array}{c}\text { Grupo } 1 \\
(300 \mathrm{mg} / \mathrm{kg})\end{array}$ & $\begin{array}{c}\text { Grupo } 2 \\
(1.500 \mathrm{mg} / \mathrm{kg})\end{array}$ & $\begin{array}{c}\text { Grupo 3 } \\
(3.000 \mathrm{mg} / \mathrm{kg})\end{array}$ & $\begin{array}{c}\text { Grupo } 4 \\
(300 \mathrm{mg} / \mathrm{kg})\end{array}$ \\
\cline { 2 - 5 } & U. F. C. & U. F. C. & U. F. C. & U. F. C. \\
\hline 1 & 0 & 100 & 0 & 0 \\
2 & 0 & 10 & 20 & 0 \\
3 & 0 & 0 & 160 & 0 \\
4 & 0 & 0 & 20 & 0 \\
5 & 20 & 0 & 65 & 0 \\
7 & 0 & 2.345 & 10 & 0 \\
8 & 0 & 0 & 160 & 0 \\
9 & 0 & 0 & 0 & 0 \\
\end{tabular}

Contactantes

\begin{tabular}{|c|c|c|c|c|}
\hline 10 & 0 & 0 & 0 & 0 \\
\hline 11 & 0 & 0 & 0 & 0 \\
\hline 12 & 0 & 0 & 0 & 0 \\
\hline 13 & 0 & 0 & 0 & 0 \\
\hline 14 & 0 & 0 & 100 & 0 \\
\hline 15 & 0 & 0 & 0 & 0 \\
\hline 16 & 0 & 0 & 0 & 0 \\
\hline 17 & 70 & 0 & 0 & 0 \\
\hline 18 & 0 & 0 & 0 & 0 \\
\hline
\end{tabular}

Tabela 2 - Número de unidades formadoras de colônias (U.F.C.) de Edwardsiella tarda isoladas de tecido hepático de alevinos de Tilápia do Nilo (Oreochromis niloticus) alimentados com doses normais de manutenção (300 mg/ kg) e megadoses de vitamina C $(1.500 \mathrm{mg} / \mathrm{kg}$ e $3.000 \mathrm{mg} / \mathrm{kg})$ durante 14 dias, experimentalmente infectados no $36^{\circ}$ dia do estudo (Experimento 2).

\begin{tabular}{ccccc}
\hline Peixes & $\begin{array}{c}\text { Grupo } 1 \\
(300 \mathrm{mg} / \mathrm{kg})\end{array}$ & $\begin{array}{c}\text { Grupo } 2 \\
(1.500 \mathrm{mg} / \mathrm{kg})\end{array}$ & $\begin{array}{c}\text { Grupo } 3 \\
(3.000 \mathrm{mg} / \mathrm{kg})\end{array}$ & $\begin{array}{c}\text { Grupo } 4 \\
(300 \mathrm{mg} / \mathrm{kg})\end{array}$ \\
\cline { 2 - 5 } & U. F. C. & U. F. C. & U. F. C. & U. F. C. \\
\hline 1 & 620 & 85 & 1.300 & 0 \\
2 & 505 & 315 & 4.260 & 0 \\
3 & 280 & 70 & 6.720 & 0 \\
4 & 4.100 & 1.370 & 395 & 0 \\
5 & 100 & 30 & 0 & 0 \\
6 & 55 & 10 & 995 & 0 \\
7 & 0 & 1.260 & 10 & 0 \\
8 & 1.050 & 0 & 46.650 & \\
9 & 1.150 & 0 & 260 & 0 \\
Contactantes & & & & 0 \\
10 & 10 & 0 & 0 & 0 \\
11 & 0 & 0 & 0 & 0 \\
12 & 0 & 0 & 0 & 0 \\
13 & 0 & 0 & 0 & 0 \\
15 & 0 & 20 & 0 & 0 \\
17 & 0 & 10 & 0 & 0 \\
\hline
\end{tabular}


A comparação dos $\log 10$ das UFC entre os experimentos 1 e 2 (Teste de Kruskal-Wallis) mostrou que houve diferença significativa $(p=0,0002)$, observando-se uma maior contagem no experimento 2 .

Como pode ser observado nas Tabelas 1 e 2, foi possível isolar cepas de E. tarda em seis animais contactantes, confirmando a possibilidade de transmissão horizontal no meio aquático da infecção em peixes não inoculados quando em convívio com peixes inoculados com a bactéria.

\section{DISCUSSÃO}

As contagens da UFC dos animais inoculados com as diferentes concentrações de E. tarda, emambos os experimentos, mostraram que estas se multiplicaram no tecido hepático de Tilápias do Nilo o que também foi observado por SANTOS et al. (2006) que reisolaram E. tarda de fígado e rim de Tilápias do Nilo, 30 dias após a inoculação intracelomática de $1,5 \times 10^{8}$ UFC/mL. VendemiatTi et al. (2003), após banhos de imersão contendo $1,5 \times 10^{4}$ e 3,92 × $10^{5} \mathrm{UFC} / \mathrm{mL}$ da bactéria, conseguiram isolar o agente do fígado de peixes da mesma espécie.

As contagens de E. tarda isolada de tecido hepático, quandocomparadas as diferentes suplementações com vitamina $C$, mostraram que não houve diferença significativa tanto para o experimento $1(p=0,1718)$ quanto para o experimento $2(\mathrm{p}=0,1411)$. Esses resultados corroboram com Li et al. (1993) que, em estudos com o bagre-de-canal (Ictalurus punctatus), concluíram que dietas com altas doses de ácido ascórbico parecem ser ineficientes como tratamento profilático visando um aumento na resistência contra a bactéria Edwardsiella ictaluri. ANDRAde et al. (2006), em experimento com matrinxã (Brycon amazonicus) inoculados experimentalmente com Aeromonas hydrophila e suplementados com $800 \mathrm{mg} / \mathrm{kg}$ deácido ascórbico, demonstraram que não houve a indução de uma resposta fisiológica diferenciada. Enquanto que CAVICHIOlo et al. (2002) comentaram que é desnecessário o uso de vitamina C em níveis superiores a 300 $\mathrm{mg} / \mathrm{kg}$ de ração, sendo este nível suficiente para atingir as exigências nutricionais de alevinos de Tilápia.

Contudo, para outros autores, as dietas suplementadas com elevados níveis de vitamina $C$ podem ter efeito benéfico não só na prevenção de doenças em animais saudáveis, como também no aumento da resistência a infecções em peixes já imunocomprometidos (Pezzatoet al., 2004; Lim etal., 2005). Li;LovelL (1985) estudaram o efeito de megadoses de vitamina C para bagre-do-canal (I. punctatus), experimentalmente infectados com Edwardsiella ictaluri, e observaram que nas dietas não suplementadas a mortalidade foi de $100 \%$, nas dietas suplementadas com $300 \mathrm{mg} /$ $\mathrm{kg}$ de ácido ascórbico por quilo de ração foi de 15\% enquanto que nas dietas com $3.000 \mathrm{mg} / \mathrm{kg}$ não houve mortalidade. Liu et al. (1989), testando o efeito de megadoses do ácido ascórbico sobre a resposta imunológica em peixes da mesma espécie que receberam $1.000 \mathrm{mg}$ de vitamina C $/ \mathrm{kg}$ da dieta, demonstraram resistência contra E. ictaluri. Segundo KuBITZA; KubitZA (1999), bagres-do-canal alimentados com rações deficientes em vitamina $C$ apresentaram menor resistência às bactérias $E$. tarda e E. ictaluri.

A comparação dos experimentos, a partir da contagem de UFC, permitiu concluir que houve uma diferença significativa entre eles $(p=0,0002)$, observando-se uma maior contagem no experimento 2 . Este resultado pode ser justificado em decorrência das concentrações bacterianas que mostraram resultados diferentes: $2,0 \times 10^{7}$ para o experimento 1 e $1,3 \times 10^{8}$ para o experimento 2 .

Outro aspecto importante está relacionado ao período entre o final da suplementação com as megadoses de vitamina $\mathrm{C}$ e o desafio. No primeiro experimento, o desafio com a $E$. tarda foi realizado após a suplementação, enquanto que no experimento 2, o desafio só ocorreu 14 dias após o término da suplementação. Considerando que o intervalo entre as duas etapas possa ter proporcionado uma diminuição dos níveis de vitamina $C$ no organismo dos peixes, o que justificaria o aumento na contagem no experimento 2, estes resultados estariam de acordo com alguns autores que sugerem a dose de $1.000 \mathrm{mg}$ de vitamina C por quilo de ração sempreque o sistema imune dos peixes for posto a prova por 2 a 4 semanas antes da ocorrência do estresse e por no mínimo, mais duas semanas após a sua ocorrência ( $\left.\mathrm{O}^{\prime} \mathrm{KeEFE}, 2001\right)$. Assim, sugerimos que a suplementação da dieta alimentar com megadoses de vitamina $\mathrm{C}$, a exemplo do quefoi observado neste estudo, poderia proporcionar aos peixes maior resistência a doenças (LI; LovelL, 1985).

Finalmente, o presente estudo mostrou pela primeira vez a possibilidade de transmissão horizontal da E. tarda em alevinos de Tilápias do Nilo, reafirmando a possibilidade de disseminação desta bactéria em ambientes aquáticos, o que pode causar sérios danos à sanidade dos plantéis aquícolas e grandes prejuízos aos criadores.

\section{CONCLUSÕES}

As concentrações testadas no presente estudo não influenciaram o grau de infecção nos alevinos de Tilápia do Nilo (O. niloticus) alimentados com as megadoses $(1.500$ e $3.000 \mathrm{mg} / \mathrm{kg}$ ) de vitamina C, além de ter sido confirmada a transmissão horizontal no 
meio aquático da infecção em peixes não inoculados quando em convívio com peixes infectados com essa bactéria.

\section{REFERENCIAS}

ALBINATI, A.C.L.; ALBINATI, R.C.B.; OLIVEIRA, E.M.D.; LABORDA, S.S.; VIDAL, L.V.O. Edwardsielose em Tilápias do Nilo (Oreochromis Niloticus). Revista Brasileira de Saúde e Produção Animal, v.7, n.2, p.164-168, 2006.

ANDRADE, J.I.A.; BRASIL, E.M.; ONO, E.A.; MATSUURA, T.; MENEZES, G.C.; FERNANDES, E.B.; SOUZA, R.Y.; OLIVEIRA, S.R.; DIAS, M.T.; AFFONSO, E.G. Influencia de dieta suplementada com vitamina $\mathrm{C}$ nas respostas fisiológicas do Matrinxã, Brycon amazonicus, após infecção por Aeromonas hydrophila. In: CONGRESO IBEROAMERICANO VIRTUAL DE ACUICULTURA, 4., 2006, Zaragoza, Espanha. Comunicaciones cientificas. Zaragoza, 2006. p.955961. Disponível em: <http:/ /www.civa2006.org/coms/ listado.asp?cod=58>. Acesso em: 14 mai. 2006.

CARTER, G.R. Procedimientos de diagnostico em bacteriologia y micologia veterinarias. Zaragosa: Acribia, 1969. 249p.

CAVICHIOLO, F.; VARGAS, L.; RIBEIRO, R.P.; MOREIRA, H.L.M.; LOURES, B.R.R.; MAEHANA, K.; POVH, J.A.; LEONARDO, J.M.L.O. Efeito da suplementação de vitamina $\mathrm{C}$ e vitamina $\mathrm{E}$ na dieta, sobre a ocorrência de ectoparasitas, desempenho e sobrevivência em larvas de tilápia do Nilo

(Oreochromis niloticus L.) durante a reversão sexual. Acta Scientiarum, v.24, n.4, p.943-948, 2002.

FALCON, D.R. Beta-glucano e vitamina C no desempenho produtivo e parâmetros fisiopatológicos da Tilápia do Nilo: nível de suplementação e tempo de administração. 2007. 146p. Tese (Doutorado - Aquicultura) - Centro de Aquicultura da Unesp, Jaboticabal, 2007.

FARIA, R.H.S.; SOUZA, M.L.R.; RIBEIRO, R.P.; FÜLBE, V.M. Avaliação de diferentes posições de marcação externa em juvenis de tilápia Oreochromis niloticus (Cichlidae). Acta Scientiarum. Animal Sciences, v.25, n.2, p.273-276, 2003.

KUBITZA, F. Tilápia: Tecnologia e planejamento na produção comercial. Jundiaí: Editora Acqua \& Imagem, 2000. 285p.

KUBITZA, F., KUBITZA, L.M.M. Principais parasitoses e doenças dos peixes cultivados. Jundiaí: Editora Acqua \& Imagem, 1999. 96p.

LI, Y.; LOVELL, R.T. Elevated levels of dietary ascorbic acid increase immune responses in channel catfish. Journal of Nutrition, v.115. p.123-131, 1985.
LI, M.H.; JOHNSON, M.R.; ROBINSON, E.H. Elevated dietary vitamin $\mathrm{C}$ concentrations did not improve resistance of channel catfish, Ictalurus punctatus, against Edwardsiella ictaluri infection. Aquaculture, v.117, n.3-4, p.303-312, 1993.

LIM, C.; YILDIRIM-AKSOY, M.; KLESIUS, P.H. Nutrition, immune response and disease resistance in fish. In: SIMPÓSIO DE NUTRIÇÃO E SAÚDE DE PEIXES, 2005, Botucatu. Anais. Botucatu, 2005. p.4683.

LIU, P.R.; PLUMB, J.A.; GUERIN, M.; LOVELL, R.T. Effect of megalevels of dietary vitamin $C$ on the immune response of channel catfish Ictalurus punctatus in ponds. Diseases of Aquatic Organisms, v.7, p.191-194, 1989.

LOVELL, R.T. Essentiality of vitamin C in feeds for intensively fed caged channel catfish. Journal of Nutrition, v.103, p.134-138, 1973.

MORAES, F.R.; MARTINS, M.L. Condições 0predisponentes e principais enfermidades de teleósteos em piscicultura intensiva. In: CYRINO,J.E.P.; URBINATI,E.C.; FRACA LOSSI,D.M.; CASTAGNOLLI, N. Tópicos especiais em Piscicultura de água doce tropical intensiva. São Paulo: TecArt, 2004. p.343-386.

$\mathrm{O}^{\prime} \mathrm{KEEFE}, \mathrm{T}$. Ascorbic acid and stable ascorbate esters as sources of vitamin $C$ in aquaculture feeds. Singapore: American Soybean Association (ASA) United Soybean Board, 2001. 8p. (ASA Technical Bulletin, AQ48-2001). Disponível em: <http:// www.asasea.com/aq48_2001.html>. Acesso em: $12 \mathrm{dez}$. 2005.

PAVANELLI, G.C.; EIRAS, J.C.; TAKEMOTO, R.M. Doenças de peixes: profilaxia, diagnóstico e tratamento. Maringá: EDUEM, 1998. 305p.

PAVANELLI, G.C.; EIRAS, J.C.; TAKEMOTO, R.M.; RANZANI-PAIVA, M.J.T.; MAGALHÃES, A.R.M.

Sanidade de peixes, rãs, crustáceos e moluscos. In: VALENTI, W.C. (Ed.) Aquicultura no Brasil: bases para um desenvolvimento sustentável. Brasília: $\mathrm{CNPq}$, Ministério da Ciência e Tecnologia, 2000. p.197-245.

PEZZATO, L.E.; BARROS, M.M.; FRACALOSSI, D.M.; CYRINO, J.E.P. Nutrição de peixes. In: CYRINO, J.E.P.; URBINATTI, E.C.; FRACALOSSI, D.M.;

CASTAGNOLLI, N. (Ed). Tópicos especiais em piscicultura de água doce tropical intensiva. São Paulo: TecArt, 2004. p.75-169.

REQUE, V.R. Efeito da suplementação alimentar com Saccharomyces cerevisiae sobre a inflamação induzida por Aeromonas hydrophila em tilápias do Nilo (Oreochromis niloticus). 2005. Dissertação (Mestrado -

Aquicultura) - Centro de Aquicultura da Unesp, Jaboticabal, 2005. 
ROBERTS, R.J. Patologia de los peces. Madrid: MundiPrensa, 1981. 366p.

SANTOS, E. S.; MOTA, S.; AQUINO, M.D.; OLIVEIRA, M.A.; VASCONCELOS, M.M.; FERNANDES, K.R.B. Alevinagem de Tilápia do Nilo, Oreochromis niloticus, em água de esgoto doméstico tratado em sistema de lagoas de estabilização. In: CONGRESO IBEROAMERICANO VIRTUAL DE ACUICULTURA, 4., 2006, Zaragoza, Espanha. Ponencias Presentadas. Zaragoza: 2006. p.274-281. Disponível em: <http:/ / www.civa2006.org>. Acesso em: 21 set. 2006.

SHIAU, S.; LIN, Y. Vitamin Requirements of Tilapia A Review. In: SIMPOSIUM INTERNACIONAL DE NUTRICIÓN ACUÍCULA, 8., Nuevo Leon, México, 2006. Anais. Nuevo Leon: 2006.

SOUZA, M. L. R. Comparação de seis métodos de filetagem em relação ao rendimento de filé e de subprodutos do processamento de Tilápia do Nilo (Oreochromis niloticus). Revista Brasileira de Zootecnia, v.31, p.1076-1084, 2002.
VENDEMIATTI, J.A.; COSTA, A.B.; CYRINO, J.E.P. Mananoligossacarídeos alimentares (MOS) como agentes profiláticos das infecções por Edwardsiella tarda em Tilápia do Nilo (Oreochromis niloticus). In: CONGRESSO IBEROAMERICANO VIRTUAL DE

ACUICULTURA, 2., 2006, Zaragoza, Espanha. Ponencias Presentadas. Zaragoza: 2003. p.132-140. Disponível em: http:/ / www.revistaaquatic.com/civa2003. Acesso em: 14 mai. 2006.

VIDAL, L.V.O.; ALBINATI, R.C.B.; SANTOS NETO, E.B.; DEUS, B.T.; ALBINATI, A.C.L. Influência do peso de juvenis de Matrinxã (Brycon cephalus) e Tambaqui (Colossoma macropomum) à ação anestésica do Eugenol. Revista Brasileira de Saúde e Produção Animal, v.8, n.3, p.212-216, 2007.

Recebido em 9/6/08

Aceito em 9/8/09 